Article

\title{
Fabrication of Novel Printable Electrically Conductive Adhesives (ECAs) with Excellent Conductivity and Stability Enhanced by the Addition of Polyaniline Nanoparticles
}

\author{
Jiayue Wen ${ }^{1}$, Yanhong Tian ${ }^{1, *}$, Chunjin Hang ${ }^{1}$, Zhen Zheng ${ }^{1}$, He Zhang ${ }^{1} \mathbb{D}$, Zhipeng Mei ${ }^{2}$, \\ Xuanyi $\mathrm{Hu}^{1}$ and Yanqing Tian ${ }^{2, *}$ \\ 1 State Key Laboratory of Advanced Welding and Joining, Harbin Institute of Technology, \\ Harbin 150001, China \\ 2 Department of Materials Science and Engineering, Southern University of Science and Technology, \\ No. 1088, Xueyuan Road, Xili, Nanshan District, Shenzhen 518055, China \\ * Correspondence: tianyh@hit.edu.cn (Y.T.); tianyq@sustech.edu.cn (Y.T.)
}

Received: 5 June 2019; Accepted: 20 June 2019; Published: 1 July 2019

\begin{abstract}
Electrically conductive adhesives (ECAs) are one of the low temperature bonding materials. It can be used to replace toxic $\mathrm{Sn}-\mathrm{Pb}$ solder. The key issue for the application of ECAs is how to improve their electrical properties. In the present study, we develop an effective method to promote the electrical properties of ECAs by addition of polyaniline (PANI) nanoparticles. PANIs were synthesized via a facile one-step chemical oxidative polymerization method. After adding $0.5 \mathrm{wt} \%$ PANI nanoparticles, the conductivity of ECAs increased dramatically by an order of magnitude. The bulk resistivity of $8.8 \times 10^{-5} \Omega \cdot \mathrm{cm}$ is achieved for $65 \mathrm{wt} \%$ silver fillers with $0.5 \mathrm{wt} \%$ PANIs loaded ECAs. Besides, this improvement has no negative effect on the shear strength and the aging life of ECAs. Moreover, the use of PANIs not only lowers the percolation threshold of ECAs, but also reduces the cost and improves the bonding reliability. Finally, PANIs enhanced ECAs patterns were successfully printed by a stencil printing method, which proved their potential applications in replacing conventional solder pastes and printing functional circuits.
\end{abstract}

Keywords: Electrically conductive adhesive; polyaniline; electrical property and reliability; low-temperature bonding; printable circuits

\section{Introduction}

In order to avoid the hazardous influence of traditional $\mathrm{Sn}-\mathrm{Pb}$ solder on human health, electrically conductive adhesives (ECAs), composed of polymer matrices and conductive fillers, are used as environmentally friendly substitutes during the bonding process [1,2]. Besides, ECAs show wider applications in low-temperature interconnection and fine-pitch packaging, and more compatibility with non-wetting substrates or flexible printed circuits (FPCs) [3,4]. Thus, ECAs are also widely applied in printable electronics [5], electromagnetic interference shielding materials [6], radio-frequency identification devices [7], thermal management materials [8], and so on.

However, an acknowledged shortcoming of ECAs is their higher electrical resistivity compared to conventional solders, which is usually considered to be caused by surface status (such as remaining organic lubricants), and the higher melting point of conducive fillers [9] compared with tin-based solders. Therefore, surface treatment technology is widely used to improve conductivity by reducing the metal oxide or decreasing the thickness of lubricant layers $[10,11]$. For example, halogen elements were used to remove the $\mathrm{Ag}_{2} \mathrm{O}$ in silver-based ECAs [12] and high-temperature treatment method 
was used to remove the organic layers on the surface of conductive fillers [13]. But bare silver fillers without an oxide layer may oxidize again during storage or thermal curing. The lack of lubricants would also cause higher viscosity and degraded fluidity.

Therefore, adding other materials, especially nanomaterials, became another strategy to improve conductivity [14-16]. From 0D nanomaterials (silver nanoparticles [17]) to 1D nanomaterials (silver nanowires [18] or CNTs [19]), from 2D graphene [20] to 3D structural nanomaterials (silver dendrites [21]), from conductors to insulators [22,23], mixing an appropriate second phase materials into ECAs can significantly improve conductivity. However, there are still many barriers in the application such as expensive synthesis costs of silver nanowires or poor dispersion of graphene.

Although improving the conductivity of ECAs is a core issue, the deterioration of fluidity [13], the decrease of shear strength [24], and the poorer thermal stability due to the addition of silver nanomaterials or graphene described in the previous paragraph should not be ignored. Consequently, enhancing the conductivity of ECAs without affecting other properties, such as reliability or printability, is also required for them to replace the traditional solders.

In addition, polyaniline (PANI) is one of the most promising intrinsic conducting polymers. Its conductivity can be as high as conductors by choosing appropriate dopants [25] and improving crystallinity [26]. Therefore, PANI composites showed growing potential in such applications as thermoelectric materials [27], conductive materials [28], supercapacitors materials [29], and electromagnetic interference shielding materials [30]. Besides, PANI could also serve as the coupling agent to improve the thermal, mechanical, and flame retardant properties of epoxy resin [31-34]. However, epoxy resin is the most-common adhesive used in ECAs due to its excellent bonding property, good environmental resistance, and excellent thermal properties $[12,13]$. Therefore, PANI is very likely to become a reinforcing material for ECAs. However, there is a lack of research on trace amount of PANI as a dopant to improve the electrical properties of silver-epoxy-based conductive composites.

Herein, we proposed a simple and effective method for improving the electrical conductivity of conventional ECAs by adding a small amount of PANI nanoparticles, namely PANIs-enhanced ECAs (PECAs). The PECAs hybrid composites, as a substitution of $\mathrm{Sn}-\mathrm{Pb}$ solders, Pb-free solders, or conventional ECAs, possess relatively low bonding temperature and high reliability whilst lower cost. After adding a small amount of PANI nanoparticles, the conductivity of ECAs increased dramatically by an order of magnitude. Mechanical shearing tests and aging experiments were also firstly performed systematically to ensure stable properties of ECAs after enhanced by PANIs. Finally, we successfully printed advanced functional circuits with PECAs materials.

\section{Materials and Methods}

\subsection{Materials}

Aniline (ANI), sodium dodecyl sulfate (SDS), methylhexahydrophthalic anhydride (MeHHPA), 2,4,6-tris(dimethylaminomethyl) phenol (DMP-30) and acetone were purchased from Aladdin, Shanghai, China. Ferric chloride hexahydrate $\left(\mathrm{FeCl}_{3} \cdot 6 \mathrm{H}_{2} \mathrm{O}\right)$ was purchased from Tianjin Fuchen Chemical Reagents Factory, Tianjin, China. Ag flakes with average diameters of 8-10 $\mu \mathrm{m}$ were purchased from Bolong Silver Industry, Changsha, China. Liquid bisphenol-A epoxy resin (E51) was purchased from Beijing Tonglian Hengxing Technology Co., Ltd., Beijing, China.

\subsection{Synthesis of PANIs Nanoparticles}

The PANI nanoparticles were synthesized by the chemical oxidation polymerization process and the size of the particles was adjusted by the usage of surfactants [35-37]. Typically, 1 mmol ANI and $10 \mathrm{mmol}$ (SDS) were dissolved in $20 \mathrm{~mL}$ DI water. Then, $5 \mathrm{~mL} \mathrm{FeCl} \mathrm{F}_{3} \cdot 6 \mathrm{H}_{2} \mathrm{O}(1 \mathrm{M})$ was added into the above solution. The solutions were stirred magnetically for $4 \mathrm{~h}$ while the vessel containing the solution was cooled in an ice bath. Finally, black emerald green precipitates were produced and washed several times with DI water and acetone. Then, the products, namely PANIs, were dried in a vacuum oven. 


\subsection{Preparation of ECAs}

Epoxy was chosen as the resin matrix. Typically, the epoxy resin, MeHHPA (curing agent) and DMP-30 (curing catalyst) were mixed with a mass ratio of 100:86:0.5. Different amount of silver flakes were fixed into epoxy uniformly by a mixing deaerator (SIE-MIX80, Sienox Industrial Products Ltd. Guangzhou, China) at $2500 \mathrm{rpm}$ for $5 \mathrm{~min}$. Combined with our previous research [38], the curing temperature of the resin was set to $150{ }^{\circ} \mathrm{C}$, which is very suitable for low temperature interconnect requirements on the field of electronic packaging. Simultaneously, different amount of PANIs (from 0 to $1.5 \mathrm{wt} \%$ ) were also fixed into epoxy to enhance the performance of ECAs. Scheme 1 illustrated the integrated fabricating procedure of PANIs enhanced conductive adhesives composites. The films of ECAs on the surfaces of glass slides were prepared by knife coating for the resistivity test. High-conductivity tracks were stencil printed on the PET substrates with the thickness of $100 \mu \mathrm{m}$.

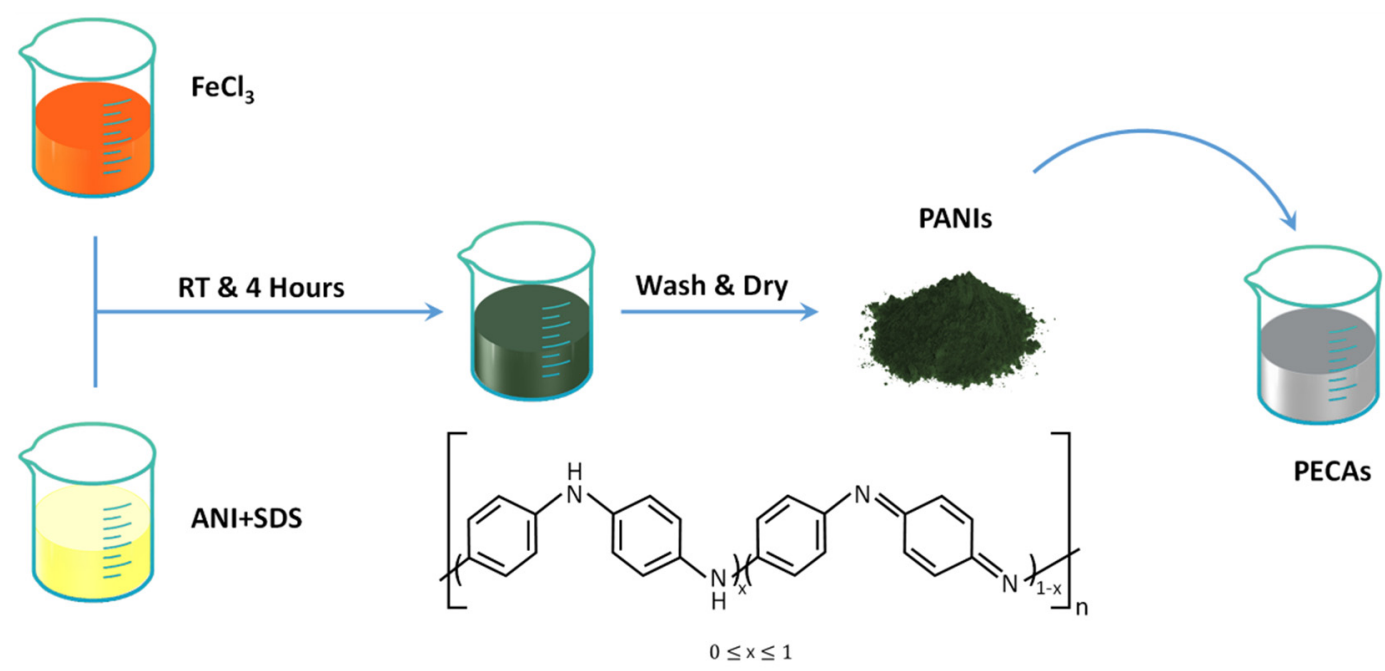

Scheme 1. Illustration of the synthesis of polyanilines (PANIs) by chemical oxidation polymerization process and fabrication of PANIs-enhanced electrically conductive adhesives (PECAs) with excellent electrical property.

\subsection{Characterization}

Scanning electron microscopy (Helios Nanolab 600i, FEI NanoPorts, FEI Corporation, OR, USA) was used to characterize the morphologies of PANI nanoparticles operated at an accelerating voltage of $20 \mathrm{kV}$ and an accelerating current of $2 \mu \mathrm{A}$. Energy dispersive X-ray spectroscopy (EDX, Helios Nanolab 600i, FEI NanoPorts, FEI Corporation, OR, USA) was used to analyze the elemental distributions of the composite. XRD patterns were collected by X-ray diffractometer (D8-ADVANCE, Bruker Corp., Rheinstetten, Germany) with $\mathrm{Cu} \mathrm{K} \alpha$ radiation $(\lambda=1.5418 \AA)$ at $40 \mathrm{kV}$ and $40 \mathrm{~mA}$. A four-point probes system (RTS-9, 4 PROBES TECH, Guangzhou, China) was used to test the sheet resistivity of ECAs films and then deducing electrical resistivity. For each condition, each sample was tested 10 times to calculate the average parameters and errors. Shear strength test was performed at room temperature by using a pull tester (DAGE 4000). The shear height of the blade tip above the Cu substrate was $0.5 \mathrm{~mm}$ and the shear speed was $100 \mu \mathrm{m} / \mathrm{s}$.

\section{Results and Discussion}

\subsection{Experimental Results and Discussion}

When using suitable polymeric stabilizers, PANI particles can be protected from macroscopic aggregation and aniline would be polymerized into the spherical nanoparticles spontaneously [39]. Figure 1a shows the morphology of PANI nanoparticles and histograms of diameter distribution. The diameter of PANI nanoparticles was controlled to $77.0 \pm 17.7 \mathrm{~nm}$ by dispersion polymerization. 
In the PANI X-Ray Diffraction specimen (Figure 1b), the crystalline peaks appeared at $2 \theta=9.1^{\circ}, 14.8^{\circ}$, $20.6^{\circ}, 25.1^{\circ}, 26.5^{\circ}$, and $29.8^{\circ}$ corresponding to (001), (011), (020), (200), (121), and (022) reflections [40]. As shown in Figure 1c, silver flakes with a diameter of 8-10 $\mu \mathrm{m}$ were selected as conductive fillers for conventional ECAs in this work. Figure 1d shows the XRD pattern of silver micro-flakes and the $2 \theta$ peaks observed at $38.1^{\circ}, 44.4^{\circ}, 64.5^{\circ}$, and $77.4^{\circ}$ corresponds to (111), (200), (220), and (311) reflection planes of a fcc lattice of silver.
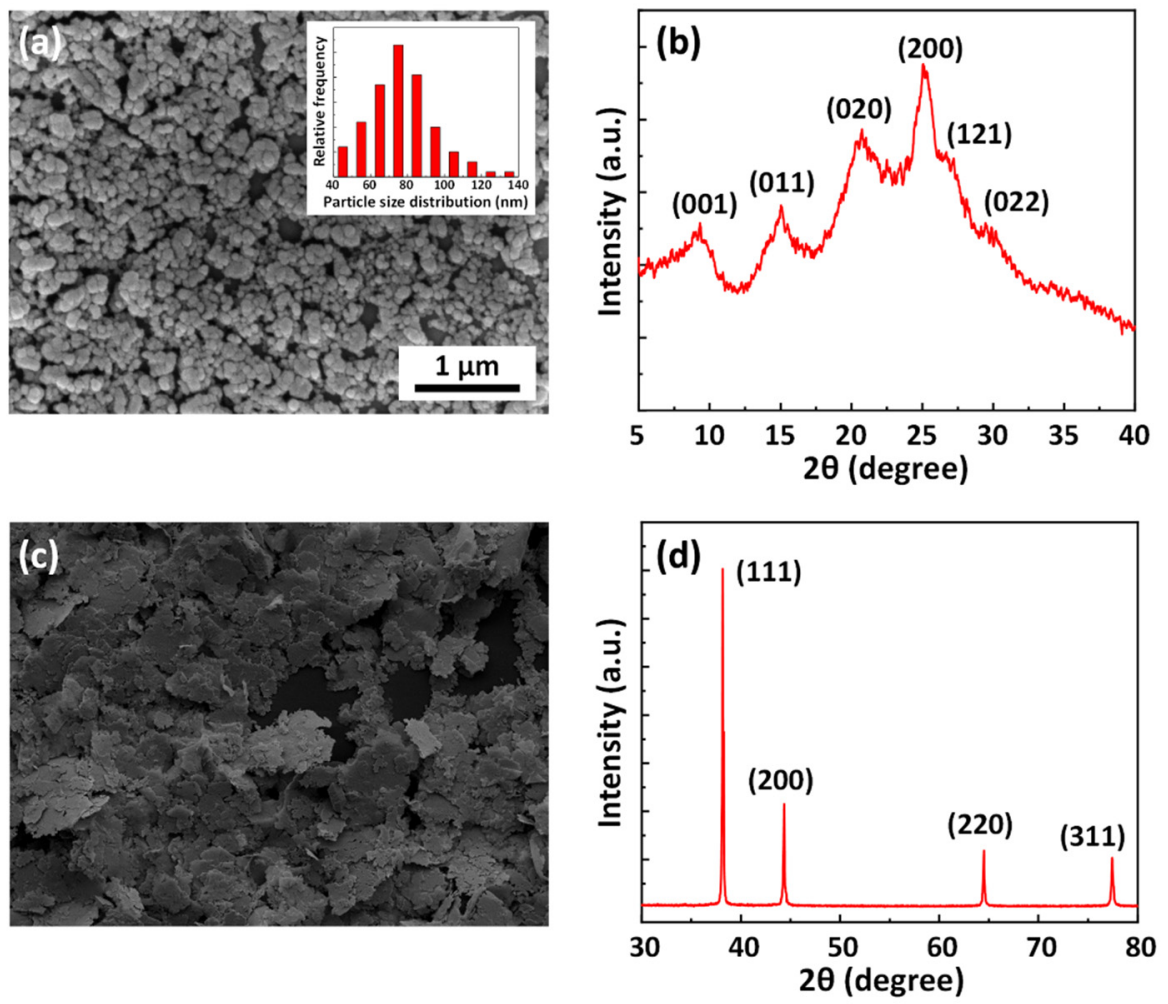

Figure 1. (a) SEM image of as-prepared nano-structure PANIs (insert: diameter distribution of PANI nanoparticles); (b) XRD spectra of as-prepared PANI materials; SEM image (c) and XRD spectra (d) of silver flakes.

\subsection{Electrical Properties of PECAs}

PECAs were prepared by adding a small amount of PANIs into conventional ECAs. As shown in the inset images of Figure 2, PECAs and conventional ECAs were similar in appearance. Figure 2 showed the comparison of conductivity of ECAs with and without $0.5 \mathrm{wt} \%$ PANIs dopants. Although the conductivity of ECAs also improves as more silver filler is added, resistivity of ECAs is further reduced by the addition of $0.5 \mathrm{wt} \%$ PANIs. The bulk resistivity decreased from $286.8 \times 10^{-5} \Omega \cdot \mathrm{cm}$ to $26.1 \times 10^{-5} \Omega \cdot \mathrm{cm}$ for $65 \mathrm{wt} \%$ silver-filled ECAs.

Macroscopically, the electrical resistance of ECAs conforms to percolation theory. The electrical conductivity of conductive composites follows the power-law relationship:

$$
\sigma=\sigma_{0}\left(M-M_{\mathcal{C}}\right)^{t}
$$

where $\sigma$ is the conductivity of the composite, $\sigma_{0}$ is the intrinsic conductivity of the filler, $M$ is the mass fraction of the filler, $M_{\mathcal{C}}$ is the critical percolation threshold, and $t$ is the power law exponent [41]. The addition of PANIs could also be considered as reducing the percolation threshold of silver-flake-filled ECAs from about $60 \mathrm{wt} \%$ to lower than $50 \mathrm{wt} \%$, which facilitates printing the pastes and reducing the cost of the ECAs. 


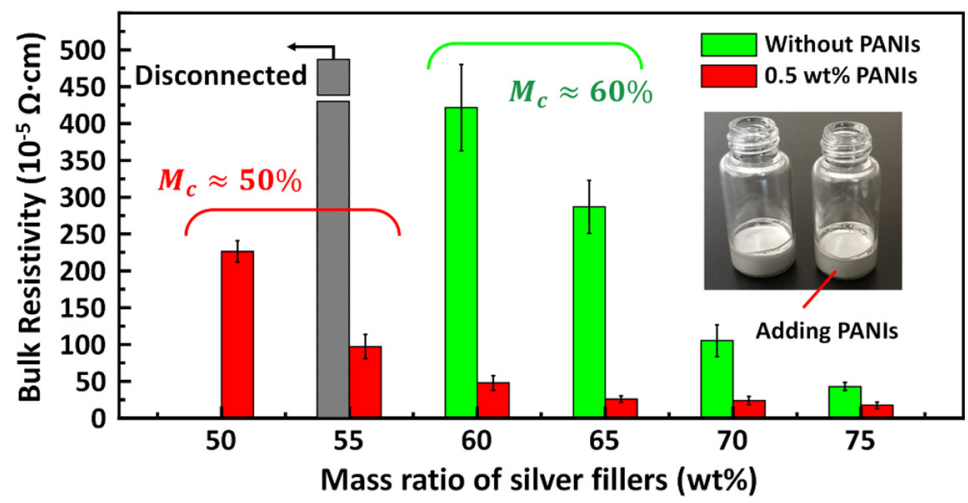

Figure 2. The comparison of bulk resistivity of electrically conductive adhesives (ECAs) between with $0.5 \mathrm{wt} \%$ or without PANIs dopants. Illustration shows the as-prepared silver-based ECA pastes with (right) or without (left) PANIs.

Figure 3a shows the change in ECAs resistivity (with $65 \mathrm{wt} \%$ silver fillers) as the mass ratio of PANI fillers is increased. A sharp resistivity drop (from $286.8 \times 10^{-5} \Omega \cdot \mathrm{cm}$ to $28.5 \times 10^{-5} \Omega \cdot \mathrm{cm}$ ) occurred after as less as $0.25 \mathrm{wt} \%$ of PANIs were added. Further increasing PANIs to $1.5 \mathrm{wt} \%$, the resistivity of ECAs remained stable. Another comparison in electrical resistivity of epoxy-based ECAs (with different curing agents) with and without $0.5 \mathrm{wt} \%$ PANIs was shown in Figure $3 \mathrm{~b}$. The method of adding PANIs to decrease the bulk resistivity of ECAs was suitable for various epoxy-based ECAs. The composition of each conductive pastes was listed in the Table 1 . The highest conductivity could reach $8.8 \times 10^{-5} \Omega \cdot \mathrm{cm}$.
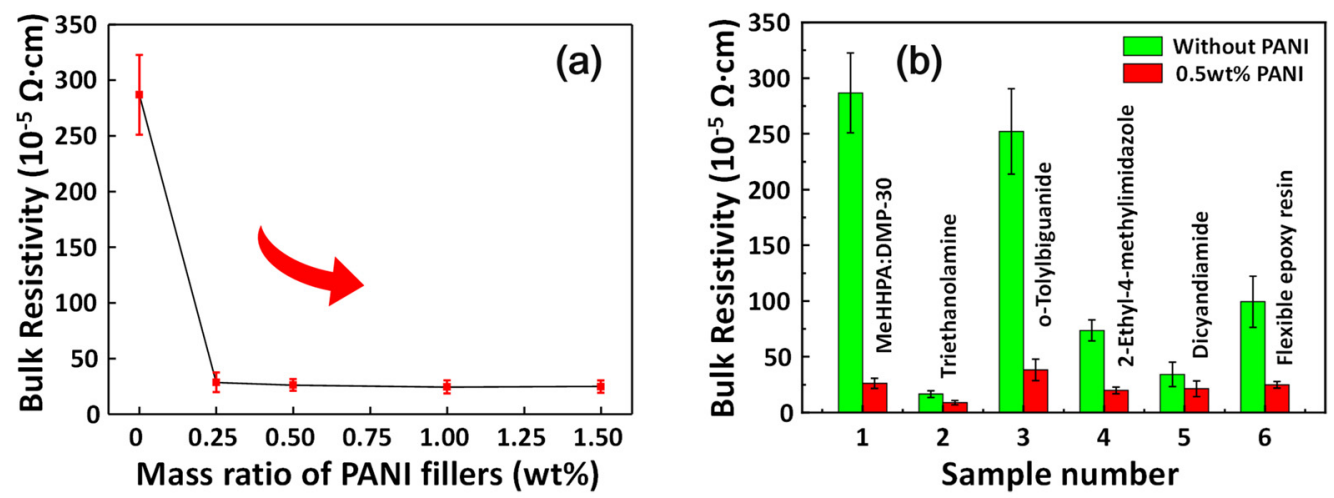

Figure 3. (a) The change trend of ECAs with adding different amount of PANIs; (b) Comparison of PANIs' improvement effect on ECAs cured with different curing agents.

Table 1. Comparison of PANIs' improvement effect on ECAs cured with different curing agents.

\begin{tabular}{ccccc}
\hline \multirow{2}{*}{ No. } & Resin Composition (Mass Ratio) & Curing Process & \multicolumn{2}{c}{ Resistivity Change $\left(\times \mathbf{1 0}^{-\mathbf{5}} \mathbf{\Omega} \cdot \mathbf{c m}\right)$} \\
\cline { 4 - 4 } & & & Without PANIs & With $\mathbf{0 . 5}$ wt $\%$ PANIs \\
\hline 1 & Epoxy: MeHHPA:DMP-30 $=(100: 85: 0.5)$ & $150^{\circ} \mathrm{C} 1 \mathrm{~h}$ & 286.8 & 26.1 \\
2 & Epoxy:Triethanolamine $=(100: 16)$ & $120^{\circ} \mathrm{C} 3 \mathrm{~h}$ & 16.7 & 8.8 \\
3 & Epoxy:0-Tolylbiguanide $=(100: 14)$ & $140^{\circ} \mathrm{C} 2 \mathrm{~h}$ & 252.2 & 38.3 \\
4 & Epoxy:2-Ethyl-4-methylimidazole $=(100: 3)$ & $120^{\circ} \mathrm{C} 1 \mathrm{~h}$ & 73.6 & 19.8 \\
5 & Epoxy: Dicyandiamide $=(100: 8)$ & $180^{\circ} \mathrm{C} 1 \mathrm{~h}$ & 34.1 & 21.4 \\
6 & Self-made modified flexible epoxy resin & $\mathrm{RT}$ & 99.4 & 25.0 \\
\hline
\end{tabular}

For the resistance of conductive composites, there are three separate contributions to the resistance: constriction resistance at the contacts, tunneling resistance at the contacts, and the intrinsic filler resistance through each particle [42]. Tunneling resistance generally dominates the magnitude of the overall resistance:

$$
R_{c}=R_{c r}+R_{t}=\rho_{i} / d+\rho_{t} / a
$$


where $R_{c}$ is the composite resistance, $R_{c r}$ is the constriction resistance, $R_{t}$ is the tunneling resistance, $\rho_{i}$ is the intrinsic filler resistivity, $d$ is the diameter of the contact spot, $\rho_{t}$ is the tunneling resistivity and $a$ is the contact spot area.

For the conduction mechanism, the addition of conductive PANIs nanomaterials is equivalent to providing more contact points for conductive composites. In our previous research [38,43], we found that there was a strong interaction between PANIs and silver flakes, which could alter the distribution of the silver flakes in the resins and enhance the tunneling state between them.

\subsection{Mechanical Property and Reliability}

The shear strength of the ECAs after addition of PANIs was measured by mechanical test equipment. Some dummy dies adhered to the bare copper substrate and the Cu/ECAs or PECAs/Cu sandwich structures were formed to test the shear strength as shown in Figure $4 \mathrm{a}, \mathrm{b}$. Figure $4 \mathrm{c}$ shows the cross-section SEM view of the joints. The line scan $\mathrm{Cu} / \mathrm{Ag} / \mathrm{C}$ element distribution curves were also marked in Figure 4c. The conductive fillers uniformly dispersed in the resin and contacted each other to form conductive paths. Epoxy and the substrate formed a tightly bonded interface ensuring electrical and mechanical properties during the ECAs connection process. Figure $4 \mathrm{~d}$ showed the shear strength changes of the ECAs with the various PANIs addition (the weight loading of silver micro-flakes was set at $60 \mathrm{wt} \%$ and $70 \mathrm{wt} \%$ respectively). In the case of $60 \mathrm{wt} \%$ silver and $0.5 \mathrm{wt} \%$ PANIs filled ECAs as an example, shear strength could reach $11.1 \pm 0.4 \mathrm{MPa}$. First, the addition of PANIs did not have a negative impact on the shear strength of ECAs. Simultaneously, it was obvious that the more the resin matrix contained, the higher the bonding strength of the conductive adhesive was. Therefore, the shear strength could only reach $7 \mathrm{MPa}$ for conventional ECAs with $70 \mathrm{wt} \%$ silver fillers with the bulk resistivity of merely $105.3 \times 10^{-5} \Omega \cdot \mathrm{cm}$. In other words, PECAs had better bonding reliability when meeting the same conductivity requirements.

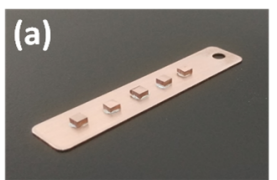

(b)

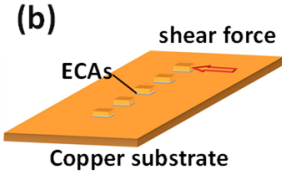

Copper substrate
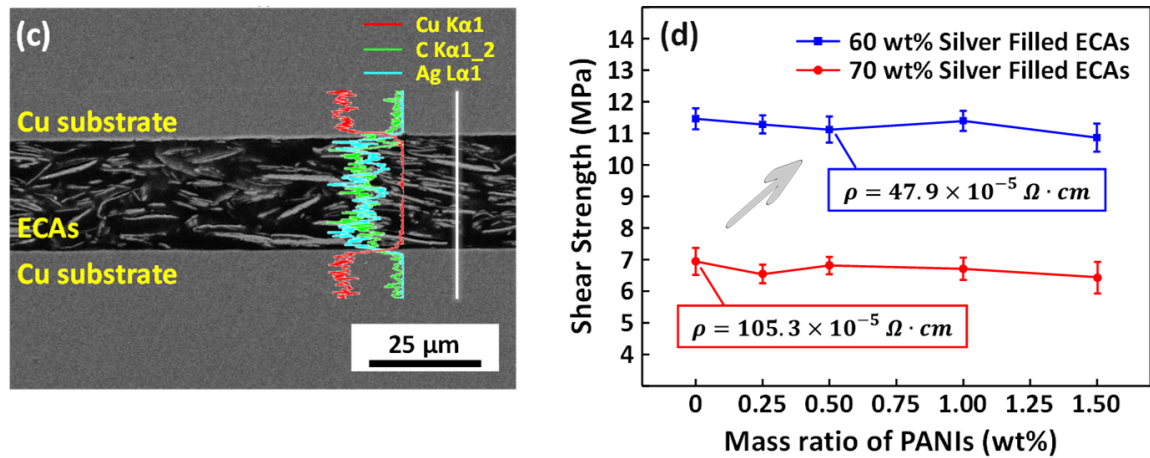

Figure 4. Photograph (a) and schematic diagram (b) of $\mathrm{Cu} / \mathrm{ECAs}$ or PECAs/Cu sandwich structure for shearing test; (c) The cross section of $\mathrm{Cu} / \mathrm{PECAs} / \mathrm{Cu}$ bonding joint and EDS line scan corresponding to the write line; (d) dependence of the shear strength of ECAs joint on the amount of adding PANIs.

It was generally acknowledged that the performance of conductive adhesives in aging tests was not as good as solder bonding. Therefore, in order to ensure the reliability of PANIs enhanced ECAs, a 600-h aging experiment at $85^{\circ} \mathrm{C}$ was performed and the electrical resistivity is shown in Figure 5a,b. The trend of electrical resistivity of ECAs with less silver fillers (60 wt $\%)$ and more silver fillers (70 wt\%). For $70 w t \%$ silver-filled ECAs with $0.5 w t \%$ PANIs dopants, the final resistivity was stable at $23.3 \times 10^{-5} \Omega \cdot \mathrm{cm}$ compared to the original resistivity $\left(24.1 \times 10^{-5} \Omega \cdot \mathrm{cm}\right)$. It was suggested that the electrical properties of PANIs enhanced ECAs would remain stable during long time high-temperature working process for the first time. 

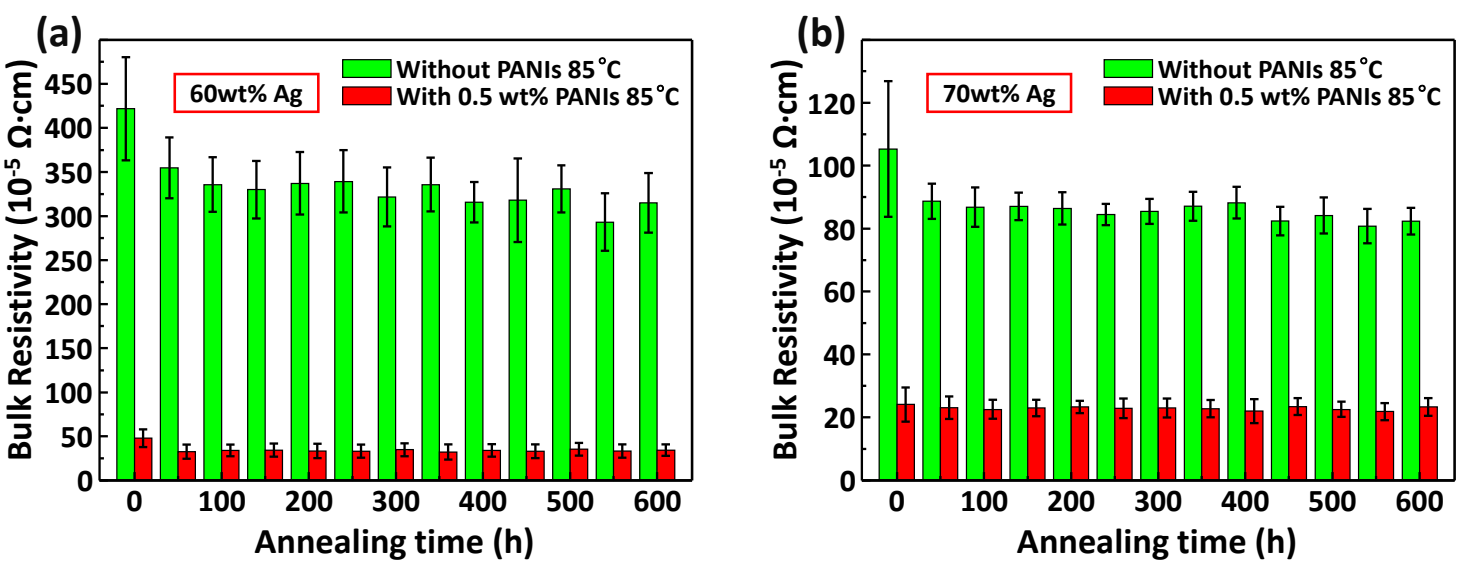

Figure 5. Bulk resistivity evolution of (a) $60 \mathrm{wt} \%$ and (b) $70 \mathrm{wt} \%$ silver-filled ECAs with or without $0.5 \mathrm{wt} \%$ PANIs during a 600 -h aging test.

\subsection{Applications}

For replacement of solder pastes, as shown in Figure 6a,b, fine-pitch PECAs pattern can be made by a stencil printing method on copper substrates. As a kind of interconnecting material instead of solders, PECAs have advantages of low process temperature and low environmental pollution. Figure $6 \mathrm{c}$ shows its excellent electrical conductivity after curing. Besides application as a kind of adhesive, advanced ECAs also need to meet the requirement in printable electronics and flexible electronics. Therefore, the adaptability of PANIs enhanced ECAs in printed electronic technologies was tested shown as Figure $6 \mathrm{~d}$,e. Since the viscosity of the conductive paste can be adjusted very easily, a radio circuit with fine-pitch and excellent conductivity can be easily printed on a flexible PET substrate.
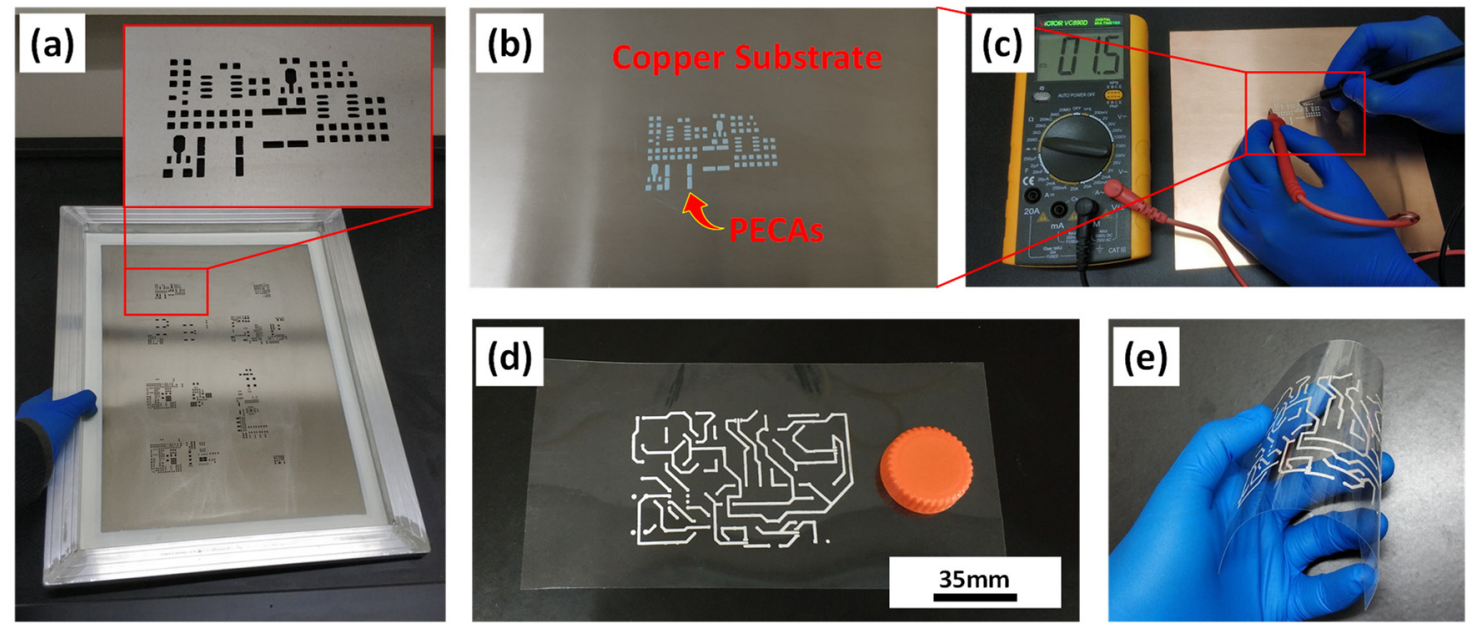

Figure 6. (a) Stencil printing mask prepared by laser beam cutting with the thickness of $100 \mu \mathrm{m}$; (b) Stencil printing PECA patterns corresponding to the mask on the copper substrate playing the same role as $\mathrm{Sn}-\mathrm{Pb}$ solders pastes; (c) Photographs of the relative resistance of the PECAs after curing; (d,e) Photographs of printable flexible circuits on a PET film. The printed circuits still maintained excellent adhesion performance during the bending process.

\section{Conclusions}

We reported an innovative method of adding PANIs into epoxy-based ECAs for improving their electrical properties. PANIs, as a kind of intrinsic conducting polymers, were added into the ECAs in the state of nanoparticles for the first time to improve the electrical performance. The bulk resistivity can decrease to as low as $8.8 \times 10^{-5} \Omega \cdot \mathrm{cm}$ and the shear strength maintain $11.1 \mathrm{MPa}$, when 
incorporating $0.5 \mathrm{wt} \%$ PANIs into $65 \mathrm{wt} \%$ silver-filled ECAs. Moreover, the bulk resistivity of PANIs enhanced ECAs was stable in the $85^{\circ} \mathrm{C}$ aging test. Therefore, PECAs showed better potential as a substitution for $\mathrm{Sn}-\mathrm{Pb}$ solder with many advantages, such as low bonding temperature or fine-pitch, compared with traditional epoxy-based ECAs. Besides, flexible PECAs have extended application for printing circuits toward the more efficient and more environmentally friendly electronic field.

Author Contributions: Conceptualization and methodology, J.W., Y.T. (Yanhong Tian), and Y.T. (Yanqing Tian); investigation and data curation, J.W., Z.M., X.H.; writing-original draft preparation, J.W.; writing-review and editing, H.Z., Z.Z., and C.H.; funding acquisition, Y.T. (Yanhong Tian) and Y.T. (Yanqing Tian).

Funding: The authors are grateful for financial support from the National Natural Science Foundation of China (Grant No. 51522503) and support from Program for New Century Excellent Talents in University (NCET-13-0175). This work was also supported partially by the High-level university construction fund for SUSTech (G01256018).

Conflicts of Interest: The authors declare no conflict of interest.

\section{References}

1. Lekawa-Raus, A.; Haladyj, P.; Koziol, K. Carbon nanotube fiber-silver hybrid electrical conductors. Mater. Lett. 2014, 133, 186-189. [CrossRef]

2. Yang, C.; Lin, W.; Li, Z.; Zhang, R.; Wen, H.; Gao, B.; Chen, G.; Gao, P.; Yuen, M.M.F.; Wong, C.P. Water-based isotropically conductive adhesives: Towards green and low-cost flexible electronics. Adv. Funct. Mater. 2011, 21, 4582-4588. [CrossRef]

3. Li, C.Y.; Liao, Y.C. Adhesive Stretchable Printed Conductive Thin film patterns on PDMS surface with an atmospheric plasma treatment. ACS Appl. Mater. Interfaces 2016, 8, 11868-11874. [CrossRef] [PubMed]

4. Suriati, G.; Mariatti, M.; Azizan, A. Effects of filler shape and size on the properties of silver filled epoxy composite for electronic applications. J. Mater. Sci. Mater. Electron. 2011, 22, 56-63. [CrossRef]

5. Zhang, T.; Li, J.; Liu, J.; Yang, J. React-on-Demand (RoD) fabrication of highly conductive metal-polymer hybrid structure for flexible electronics via one-step direct writing or printing. Adv. Funct. Mater. 2018, 28, 1704671. [CrossRef]

6. Pande, S.; Singh, B.; Mathur, R.; Dhami, T.; Saini, P.; Dhawan, S. Improved electromagnetic interference shielding properties of MWCNT-PMMA composites using layered structures. Nanoscale Res. Lett. 2009, 4, 327. [CrossRef] [PubMed]

7. Li, Z.; Le, T.; Wu, Z.; Yao, Y.; Li, L.; Tentzeris, M.; Moon, K.S.; Wong, C.P. Rational design of a printable, highly conductive silicone-based electrically conductive adhesive for stretchable radio-frequency antennas. Adv. Funct. Mater. 2015, 25, 464-470. [CrossRef]

8. Zhang, X.; Zhang, K.; Zhang, M.; Yang, C.; Sun, H.; Gao, Z.; Yuen, M.M.F.; Yang, S. Highly conductive die attach adhesive from percolation control and its applications in light-emitting device thermal management. Appl. Phys. Lett. 2013, 102, 014101. [CrossRef]

9. Li, Z.; Zhang, R.; Moon, K.S.; Liu, Y.; Hansen, K.; Le, T.; Wong, C.P. Highly conductive, flexible, polyurethane-based adhesives for flexible and printed electronics. Adv. Funct. Mater. 2013, 23, 1459-1465. [CrossRef]

10. Li, C.; Li, Q.; Long, X.; Li, T.; Zhao, J.; Zhang, K.; E, S.; Zhang, J.; Li, Z.; Yao, Y. In situ generation of photosensitive silver halide for improving the conductivity of electrically conductive adhesives. ACS Appl. Mater. Interface 2017, 9, 29047-29054. [CrossRef]

11. Wang, L.; Wan, C.; Fu, Y.; Chen, H.; Liu, X.; Li, M. Study on the effects of adipic acid on properties of dicyandiamide-cured electrically conductive adhesive and the interaction mechanism. J. Electron. Mater. 2014, 43, 132-136. [CrossRef]

12. Yang, C.; Xie, Y.T.; Yuen, M.M.F.; Xu, B.; Gao, B.; Xiong, X.M.; Wong, C.P. Silver Surface iodination for enhancing the conductivity of conductive composites. Adv. Funct. Mater. 2010, 20, 2580-2587. [CrossRef]

13. Li, C.; Li, Q.; Cheng, L.; Li, T.; Lu, H.; Tang, L.; Zhang, K.; E, S.; Zhang, J.; Li, Z.; et al. Conductivity enhancement of polymer composites using high-temperature short-time treated silver fillers. Compos. Part $A$ Appl. Sci. Manuf. 2017, 100, 64-70. [CrossRef] 
14. Matsuhisa, N.; Inoue, D.; Zalar, P.; Jin, H.; Matsuba, Y.; Itoh, A.; Yokota, T.; Hashizume, D.; Someya, T. Printable elastic conductors by in situ formation of silver nanoparticles from silver flakes. Nat. Mater. 2017, 16, 834. [CrossRef] [PubMed]

15. Patole, A.; Lubineau, G. Carbon nanotubes with silver nanoparticle decoration and conductive polymer coating for improving the electrical conductivity of polycarbonate composites. Carbon 2015, 81, 720-730. [CrossRef]

16. Nam, S.; Cho, H.W.; Kim, T.; Kim, D.; Sung, B.J.; Lim, S.; Kim, H. Effects of silica particles on the electrical percolation threshold and thermomechanical properties of epoxy/silver nanocomposites. Appl. Phys. Lett. 2011, 99, 043104. [CrossRef]

17. Amoli, B.M.; Gumfekar, S.; Hu, A.; Zhou, Y.N.; Zhao, B. Thiocarboxylate functionalization of silver nanoparticles: Effect of chain length on the electrical conductivity of nanoparticles and their polymer composites. J. Mater. Chem. 2012, 22, 20048-20056. [CrossRef]

18. Zhang, Z.X.; Chen, X.Y.; Xiao, F. The sintering behavior of electrically conductive adhesives filled with surface modified silver nanowires. J. Adhes. Sci. Technol. 2011, 25, 1465-1480. [CrossRef]

19. Hermant, M.C.; van der Schoot, P.; Klumperman, B.; Koning, C.E. Probing the cooperative nature of the conductive components in polystyrene/poly(3,4-ethylenedioxythiophene):poly(styrene sulfonate)-single-walled carbon nanotube composites. ACS Nano 2010, 4, 2242-2248. [CrossRef]

20. Ji, Y.H.; Liu, Y.; Li, Y.Q.; Xiao, H.M.; Du, S.S.; Zhang, J.Y.; Hu, N.; Fu, S.Y. Significantly enhanced electrical conductivity of silver nanowire/polyurethane composites via graphene oxide as novel dispersant. Compos. Sci. Technol. 2016, 132, 57-67. [CrossRef]

21. Yang, C.; Cui, X.; Zhang, Z.; Chiang, S.W.; Lin, W.; Duan, H.; Li, J.; Kang, F.; Wong, C.P. Fractal dendrite-based electrically conductive composites for laser-scribed flexible circuits. Nat. Commun. 2015, 6, 8150. [CrossRef] [PubMed]

22. Choi, S.; Han, S.I.; Jung, D.; Hwang, H.J.; Lim, C.; Bae, S.; Park, O.K.; Tschabrunn, C.M.; Lee, M.; Bae, S.Y.; et al. Highly conductive, stretchable and biocompatible Ag-Au core-sheath nanowire composite for wearable and implantable bioelectronics. Nat. Nanotechnol. 2018, 13, 1048-1056. [CrossRef] [PubMed]

23. Matsuhisa, N.; Kaltenbrunner, M.; Yokota, T.; Jinno, H.; Kuribara, K.; Sekitani, T.; Someya, T. Printable elastic conductors with a high conductivity for electronic textile applications. Nat. Commun. 2015, 6, 7461. [CrossRef] [PubMed]

24. Si, P.; Trinidad, J.; Chen, L.; Lee, B.; Chen, A.; Persic, J.; Lyn, R.; Leonenko, Z.; Zhao, B. PEDOT:PSS nano-gels for highly electrically conductive silver/epoxy composite adhesives. J. Mater. Sci. Mater. Electron. 2018, 29, 1837-1846. [CrossRef]

25. Zhang, H.; Lu, J.; Wang, X.; Li, J.; Wang, F. From amorphous to crystalline: Practical way to improve electrical conductivity of water-borne conducting polyaniline. Polymer 2011, 52, 3059-3064. [CrossRef]

26. Hu, Q.; Zhou, N.; Gong, K.; Liu, H.; Liu, Q.; Sun, D.; Wang, Q.; Shao, Q.; Liu, H.; Qiu, B.; et al. Intracellular polymer substances induced conductive polyaniline for improved methane production from anaerobic wastewater treatment. ACS Sustain. Chem. Eng. 2019, 7, 5912-5920. [CrossRef]

27. Wang, L.; Bi, H.; Yao, Q.; Ren, D.; Qu, S.; Huang, F.; Chen, L. Three-dimensional tubular graphene/polyaniline composites as high-performance elastic thermoelectrics. Compos. Sci. Technol. 2017, 150, 135-140. [CrossRef]

28. Fang, F.; Huang, G.W.; Xiao, H.M.; Li, Y.Q.; Hu, N.; Fu, S.Y. Largely enhanced electrical conductivity of layer-structured silver nanowire/polyimide composite films by polyaniline. Compos. Sci. Technol. 2018, 156, 144-150. [CrossRef]

29. Yuksel, R.; Durucan, C.; Unalan, H.E. Ternary nanocomposite SWNT/WO3/PANI thin film electrodes for supercapacitors. J. Alloys. Compd. 2016, 658, 183-189. [CrossRef]

30. Huangfu, Y.; Ruan, K.; Qiu, H.; Lu, Y.; Liang, C.; Kong, J.; Gu, J. Fabrication and investigation on the PANI/MWCNT/thermally annealed graphene aerogel/epoxy electromagnetic interference shielding nanocomposites. Compos. Part A Appl. Sci. Manuf. 2019, 121, 265-272. [CrossRef]

31. Gu, H.; Guo, J.; Wei, H.; Yan, X.; Ding, D.; Zhang, X.; He, Q.; Tadakamalla, S.; Wang, X.; Ho, T.C.; et al. Transparent anhydride-cured epoxy nanocomposites reinforced with polyaniline stabilized nanosilica. J. Mater. Chem. C 2015, 3, 8152-8165. [CrossRef]

32. Guo, J.; Long, J.; Ding, D.; Wang, Q.; Shan, Y.; Umar, A.; Zhang, X.; Weeks, B.L.; Wei, S.; Guo, Z. Significantly enhanced mechanical and electrical properties of epoxy nanocomposites reinforced with low loading of polyaniline nanoparticles. RSC Adv. 2016, 6, 21187-21192. [CrossRef] 
33. Zhang, X.; He, Q.; Gu, H.; Wei, S.; Guo, Z. Polyaniline stabilized barium titanate nanoparticles reinforced epoxy nanocomposites with high dielectric permittivity and reduced flammability. J. Mater. Chem. C 2013, 1, 2886-2899. [CrossRef]

34. Zhou, K.; Liu, C.; Gao, R. Polyaniline: A novel bridge to reduce the fire hazards of epoxy composites. Compos. Part A Appl. Sci. Manuf. 2018, 112, 432-443. [CrossRef]

35. Sen, T.; Mishra, S.; Shimpi, N.G. Synthesis and sensing applications of polyaniline nanocomposites: A review. RSC Adv. 2016, 6, 42196-42222. [CrossRef]

36. Tuncel, D.; Demir, H.V. Conjugated polymer nanoparticles. Nanoscale 2010, 2, 484-494. [CrossRef]

37. Pecher, J.; Mecking, S. Nanoparticles of conjugated polymers. Chem. Rev. 2010, 110, 6260-6279. [CrossRef]

38. Wen, J.; Tian, Y.; Mei, Z.; Wu, W.; Tian, Y. Synthesis of polypyrrole nanoparticles and their applications in electrically conductive adhesives for improving conductivity. RSC Adv. 2017, 7, 53219-53225. [CrossRef]

39. Abel, S.B.; Yslas, E.I.; Rivarola, C.R.; Barbero, C.A. Synthesis of polyaniline (PANI) and functionalized polyaniline (F-PANI) nanoparticles with controlled size by solvent displacement method. Application in fluorescence detection and bacteria killing by photothermal effect. Nanotechnology 2018, 29, 125604. [CrossRef]

40. Wu, K.H.; Ting, T.H.; Wang, G.P.; Ho, W.D.; Shih, C.C. Effect of carbon black content on electrical and microwave absorbing properties of polyaniline/carbon black nanocomposites. Polym. Degrad. Stabil. 2008, 93, 483-488. [CrossRef]

41. Brigandi, P.J.; Cogen, J.M.; Pearson, R.A. Electrically conductive multiphase polymer blend carbon-based composites. Polym. Eng. Sci. 2014, 54,1-16. [CrossRef]

42. Ruschau, G.R.; Yoshikawa, S.; Newnham, R.E. Resistivities of conductive composites. J. Appl. Phys. 1992, 72, 953-959. [CrossRef]

43. Wen, J.; Tian, Y.; Hao, C.; Wang, S.; Mei, Z.; Wu, W.; Lu, J.; Zheng, Z.; Tian, Y. Fabrication of high performance printed flexible conductors by doping of polyaniline nanomaterials into silver paste. J. Mater. Chem. C 2019, 7, 1188-1197. [CrossRef] 